\title{
Analysis of $0^{6}$-[4-(3-Pyridyl)-4-oxobut-1-yl]-2' -deoxyguanosine and Other DNA Adducts in Rats Treated with Enantiomeric or Racemic $\boldsymbol{N}^{\prime}$-Nitrosonornicotine
}

\author{
Jing Yang, Peter W. Villalta, Pramod Upadhyaya, and Stephen S. Hecht ${ }^{*}$ \\ Masonic Cancer Center, University of Minnesota, Minneapolis, Minnesota 55455, United States
}

\section{Abstract}

\begin{abstract}
(S)- $N^{\prime}$-nitrosonornicotine [(S)-NNN] and racemic NNN are powerful oral and esophageal carcinogens in the F-344 rat while $(R)$-NNN has only weak activity. Tumor formation in these tissues of rats treated with racemic NNN was far greater than the sum of the activities of the individual enantiomers. We hypothesized that metabolites of $(R)$-NNN enhanced levels of DNA adducts produced by $(S)$-NNN. A test of that hypothesis necessitated the development of a novel liquid chromatography nanoelectrospray ionization high-resolution tandem mass spectrometry method for the analysis of $O^{6}$-[4-(3-pyridyl)-4-oxobut-1-yl]-2' -deoxyguanosine ( $O^{6}$-POB-dGuo), a highly mutagenic DNA adduct not previously quantified in rats treated with NNN. The new method, with a limit of detection of 6.5 amol for diluted standard and 100 amol for DNA samples, was applied in this study. Groups of 9 F344 rats were treated with doses as follows: 7 ppm $(R)$ NNN, 7 ppm ( $S$ )-NNN and 14 ppm racemic NNN; 14 ppm $(R)$-NNN, 14 ppm $(S)$-NNN and 28 ppm racemic NNN; or $28 \mathrm{ppm}(R)$-NNN, $28 \mathrm{ppm}(S)$-NNN and $56 \mathrm{ppm}$ racemic NNN for 5 weeks, and tissues were analyzed for DNA adducts. We found statistically significant, but modest, synergistic enhancement of levels of $O^{6}$-POB-dGuo in the esophagus but not the oral cavity of rats treated with racemic NNN (low and median doses only) compared to the sum of the amounts formed in these tissues of rats treated with $(S)$-NNN or $(R)$-NNN. There was no synergy in the formation of other POB-DNA adducts of NNN in oral cavity and esophagus, nor was there any evidence for synergy in nasal respiratory and olfactory epithelium, lung, or liver. Our results provide the first quantitation of $O^{6}$-POB-dGuo in DNA from tissues of rats treated with NNN, and evidence for synergy in DNA adduct formation as one possible mechanism by which $(R)$-NNN enhances the carcinogenicity of $(S)$-NNN in rats.
\end{abstract}

\section{Graphical abstract}

\footnotetext{
*To whom correspondence should be addressed: Masonic Cancer Center, University of Minnesota, $22316^{\text {th }}$ Street SE - 2-148 CCRB, Minneapolis, MN 55455, USA. phone: (612) 624-7604 fax: (612) 624-3869, hecht002@umn.edu.

Supporting Information:

Levels of individual and total POB-DNA adducts in rats treated with the two enantiomers and racemic NNN at three dosage levels and Scheme S1 summarizing intermediates produced upon $5^{\prime}$-hydroxylation of NNN. This material is available free of charge via the Internet at http://pubs.acs.org.

Notes:

The authors declare no competing financial interest.
} 


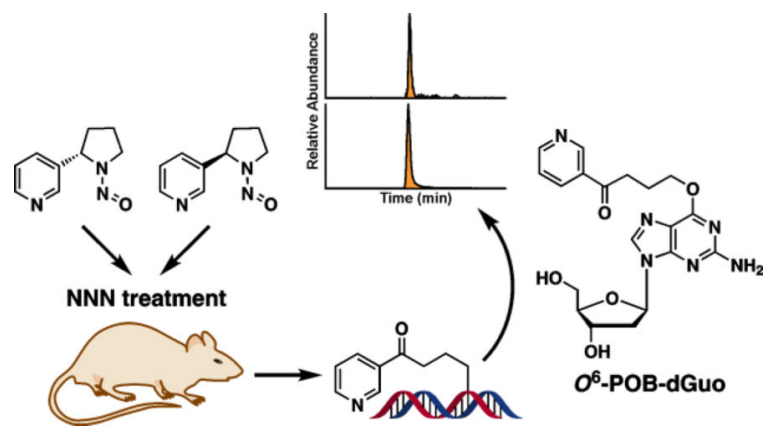

\section{Introduction}

$N^{\prime}$-Nitrosonornicotine (NNN, $\mathbf{1}$ and 2, Figure 1) is one of the most abundant and carcinogenic tobacco-specific nitrosamines present in all tobacco products. ${ }^{1} \mathrm{NNN}$ and the related tobacco-specific nitrosamine 4-(methylnitrosamino)-1-(3-pyridyl)-1-butanone (NNK, 3, Figure 1) are classified as Group I human carcinogens by the International Agency for Research on Cancer. ${ }^{2}$ Numerous carcinogenicity experiments in laboratory rats have shown that racemic NNN induces tumors in the esophagus and nasal cavity, depending on the route of administration. ${ }^{1}$ In a recent study, we demonstrated that $(S)$-NNN, administered in the drinking water to F-344 rats at a dose of 14 ppm, caused oral cavity tumors and esophageal tumors in all treated rats, with an average of 4.5 and 6.1 tumors per rat in the oral cavity and esophagus, respectively, while the same dose of $(R)$-NNN was only weakly active, causing 0.25 and 0.13 esophageal and oral cavity tumors per rat, respectively. ${ }^{3}$ Interestingly, treatment with $28 \mathrm{ppm}$ racemic NNN in the same study caused 8 oral cavity tumors per rat and 13 esophageal tumors per rat, significantly higher than the additive effect of the two individual enantiomers, suggesting that the weak carcinogen $(R)$-NNN can synergistically enhance the carcinogenicity of $(S)$-NNN. ${ }^{3}$ We hypothesized that metabolites of $(R)$-NNN could enhance the levels of DNA adducts produced in the metabolism of $(S)$-NNN. This hypothesis was tested in the study reported here.

a-Hydroxylation of NNN at the $2^{\prime}$ position, catalyzed by cytochrome P450s, produces the reactive intermediate 4-(3-pyridyl)-4-oxobutane-1-diazonium ion that reacts with DNA and forms 4-(3-pyridyl)-4-oxobutyl (POB)-DNA adducts, which are believed to play an important role in NNN carcinogenesis in rats. ${ }^{4-9}$ In a metabolism study of enantiomeric NNN, cultured rat esophagus metabolized $(S)$-NNN extensively through $2^{\prime}$-hydroxylation but $(R)$-NNN was metabolized almost equally through the $2^{\prime}$ and $5^{\prime}$-hydroxylation pathways. ${ }^{10}$ This is consistent with the observation that $(S)$-NNN produces $3-5$ times more POB-DNA adducts than $(R)$-NNN in esophagus and oral mucosa $8,9,11$ and with the carcinogenicity data, ${ }^{3}$ but DNA adduct formation from enantiomeric and racemic NNN has never been compared previously.

Individual POB-DNA adducts identified in NNN-treated rat tissues are: $O^{6}$-[4-(3-pyridyl)-4oxobut-1-yl]-2' -deoxyguanosine ( $O^{6}$-POB-dGuo, 4), $O^{2}$-[4-(3-pyridyl)-4-oxobut-1yl]thymidine ( $O^{2}$-POB-dThd, 5), 7-[4-(3-pyridyl)-4-oxobut-1-yl]-2' ${ }^{\prime}$-deoxyguanosine (7POB-dGuo, 6), and $O^{2}$-[4-(3-pyridyl)-4-oxobut-1-yl]-2' -deoxycytidine ( $O^{2}$-POB-dCyd, 7). 
The latter two are released upon neutral thermal hydrolysis and measured as the stable deribosylated adducts 7-[4-(3-pyridyl)-4-oxobut-1-yl]guanine (7-POB-Gua, 8) and $O^{2}$-[4-(3pyridyl)-4-oxobut-1-yl]cytosine ( $O^{2}$-POB-Cyt, 9), respectively. Among these DNA adducts, $O^{2}$-POB-dThd and 7-POB-Gua were the most abundant in all tissues. $O^{6}$-POB-dGuo has only been detected occasionally in tissues of NNN-treated rats, but never previously quantified.

Albeit present in low levels, $O^{6}$-POB-dGuo has the greatest mutagenicity among the four identified POB-DNA adducts. $O^{6}$-Substituted guanine adducts lead to misincorporation of thymine thus inducing GC to AT transitions. ${ }^{12,13} O^{6}$-POB-dGuo induces $\mathrm{G}$ to A transitions in bacteria; in human HEK-293 cells, $O^{6}$-POB-dGuo induces mainly G to A transitions, as well as a small number of $\mathrm{G}$ to $\mathrm{T}$ transversions, more complex multiple mutations and remote mutations together with deletions. ${ }^{14} O^{6}$-POB-dGuo has been previously identified and quantified in NNK- or NNKOAc-treated mouse and rat tissues by HPLC with radioflow detection ${ }^{15}$ and by mass spectrometry, ${ }^{16-18}$ but it has never been quantified in tissues of animals treated with NNN due to insufficient sensitivity. In the study described here, we report the first quantitation of $O^{6}$-POB-dGuo in tissues of NNN-treated rats, using liquid chromatography-nanoelectrospray ionization-high resolution tandem mass spectrometry with accurate mass detection (LC-NSI-HRMS/MS). Levels of this adduct as well as the other POB-DNA adducts were evaluated with respect to our hypothesis that metabolites of $(R)$-NNN could enhance DNA adduct levels caused by $(S)$-NNN, thus potentially accounting for the synergistic carcinogenicity of racemic NNN in the rat oral cavity and esophagus.

\section{Experimental procedures}

\section{Caution}

(R)-NNN, (S)-NNN and racemic NNN are carcinogenic. They should be handled in a wellventilated hood with extreme care and appropriate protective equipment.

\section{Chemicals}

$(R)-\mathrm{NNN},(S)$-NNN and racemic NNN were synthesized as described previously. ${ }^{19,}{ }^{20}$ POBDNA standards and deuterium labeled internal standards were synthesized previously in our laboratory. ${ }^{17,21-23}$ Puregene DNA purification solutions, proteinase K and RNase A were purchased from Qiagen (Valencia, CA). Calf thymus DNA and micrococcal nuclease (from Staphylococcus aureus) were from Worthington Biochemical (Lakewood, NJ).

Phosphodiesterase II (from bovine spleen) was purchased from Sigma-Aldrich (St. Louis, MO). Alkaline phosphatase (from calf intestine) was obtained from Roche Diagnostics (Indianapolis, IN). All other chemicals were from Sigma-Aldrich or Fisher Scientific (Fairlawn, NJ).

\section{Animal Experiment}

This study was approved by the University of Minnesota Institutional Animal Care and Use Committee. Eighty-one 6-week-old male F344 rats, purchased from Charles River Laboratories (Kingston, NY), were housed two rats per micro-isolator cage with Harlan Teklad 1/4-inch corn cob bedding (Harlan, Indianapolis, IN) in the Research Animal 
Resources facility under the following conditions: $20-24{ }^{\circ} \mathrm{C}, 30-70 \%$ relative humidity, and $12 / 12 \mathrm{~h}$ light/dark cycle. These rats were randomly divided into nine treatment groups of nine rats each at three different dose level combinations. The three groups in the low dosage level were given appropriate carcinogens at the following concentrations: $7 \mathrm{ppm}(R)-\mathrm{NNN}, 7 \mathrm{ppm}$ $(S)$-NNN and $14 \mathrm{ppm}$ racemic NNN. The median dosage level groups were: $14 \mathrm{ppm}(R)$ NNN, 14 ppm (S)-NNN and $28 \mathrm{ppm}$ racemic NNN. The high dosage level groups were: 28 ppm $(R)$-NNN, $28 \mathrm{ppm}(S)$-NNN and $56 \mathrm{ppm}$ racemic NNN. After the rats acclimated to the facility environment for two weeks, they were given the desired concentrations of appropriate carcinogens in drinking water for 5 weeks. According to our previous experiments, POB-DNA adduct formation reached a plateau after about 5 weeks' treatment with NNN at similar doses. ${ }^{8,9,11}$ During the treatment, the rats were fed Harlan Teklad 2018 diet, and their drinking bottles containing NNN solutions were changed twice a week. The stock NNN solutions were made prior to the treatment and kept at $4{ }^{\circ} \mathrm{C}$. Their concentrations were monitored over the course of treatment by HPLC and the variation was within 5\% relative standard deviation (RSD). NNN consumption was measured twice a week and their body weights were measured every two weeks. There was no significant difference in water consumption and there were no effects of carcinogen treatment on body weights for the different treatment groups. At the end of 5 weeks of treatment, the rats were humanely euthanized by $\mathrm{CO}_{2}$ overdose and tissues were harvested and stored at $-80{ }^{\circ} \mathrm{C}$ until DNA isolation.

\section{Tissue Harvest}

After the rats were euthanized, lung, liver, esophageal mucosa, oral mucosa, nasal respiratory and olfactory mucosa were harvested as previously described. $7,9,11,18$ Briefly, lung and liver were harvested from each rat. Esophagus was isolated and cut lengthwise to open the esophageal tube and retrieve the inner mucosa layer. In the oral cavity, the mucosa from each side and the surface layer of the tongue were collected. For nasal cavity tissue retrieval, the rat head was placed with the palate facing up. The head was split by cutting through the hard palate longitudinally on the median line using a bone mallet and a blade. Nasal respiratory mucosa was retrieved from naso- and maxillo-turbinates, lateral wall of the nasal passage and median septum anterior to the olfactory area. Nasal olfactory mucosa was retrieved from ethmo-turbinates, the lateral wall and the septum of the olfactory area. The tissues were stored at $-80{ }^{\circ} \mathrm{C}$ until DNA isolation.

\section{Sample Preparation for POB-DNA Adducts Analysis}

DNA was isolated and purified from the tissues by following the Gentra Puregene protocol (Qiagen, Valencia, CA) with modifications as described previously ${ }^{24}$ except $\mathrm{NaBH}_{3} \mathrm{CN}$ was not used. Lung and liver DNA was isolated from 3 rats individually. Esophageal mucosa, oral mucosa, nasal respiratory and olfactory mucosa from 9 rats were pooled into 3 samples for DNA isolation. DNA hydrolysis and sample clean-up were carried out as described previously. ${ }^{16,17}$ Briefly, 0.1-2 mg of DNA was dissolved in succinate buffer and four deuterated internal standards of POB-DNA adducts were added. After neutral thermal hydrolysis $\left(100^{\circ} \mathrm{C}, 30 \mathrm{~min}\right)$, the DNA was further hydrolyzed by micrococcal nuclease, phosphodiesterase II and alkaline phosphatase. The hydrolysate was filtered using an Amicon centrifugal filter unit with membrane NMWL of $30 \mathrm{kDa}$ (Millipore, Billerica, MA). 
A $20 \mu \mathrm{L}$ aliquot of the filtrate was taken for dGuo quantitation by $\operatorname{HPLC}^{17}$ and then used to calculate DNA amount, considering that $1 \mathrm{mg}$ DNA contains $3 \mu \mathrm{mol}$ of nucleotides and dGuo accounts for $22 \%$ of total nucleotides in rat DNA. ${ }^{25}$ The remaining filtrate was purified by Strata-X solid phase extraction (Phenomenex, Torrance, $\mathrm{CA}$ ) and the eluted fraction was concentrated to dryness and stored at $-20^{\circ} \mathrm{C}$ until further quantitation by mass spectrometry.

\section{Quantitation of POB-DNA Adducts by Liquid Chromatography-Electrospray lonization- Tandem Mass Spectrometry (LC-ESI-MS/MS)}

The dried sample was re-dissolved in $20 \mu \mathrm{L} \mathrm{H}_{2} \mathrm{O}$ and $8 \mu \mathrm{L}$ was injected for POB-DNA adduct quantitation using LC-ESI-MS/MS with selected reaction monitoring (SRM) as described previously. $8,9,11$ A Dionex UltiMate 3000 capillary HPLC system (Thermo Scientific, San Jose, CA) was coupled to a TSQ Vantage triple quadrupole mass spectrometer (Thermo Scientific). The separation was carried out on a $150 \mathrm{~mm} \times 0.5 \mathrm{~mm}$ Zorbax SB-C18 $5 \mu \mathrm{m}$ column (Agilent, Santa Clara, CA) at room temperature with a gradient from 0 to $25 \%$ of $\mathrm{CH}_{3} \mathrm{CN}$ in $15 \mathrm{mM} \mathrm{NH}_{4} \mathrm{OAc}$ in $20 \mathrm{~min}$, held for $2 \mathrm{~min}$, then returned to $0 \%$ in $1 \mathrm{~min}$ and re-equilibrated for $17 \mathrm{~min}$ at a flow rate of $15 \mu \mathrm{L} / \mathrm{min}$. The mass spectrometer was operated in positive ion mode; the selected ion transitions monitored for the POB-DNA adducts and the internal standards are listed in Table 1. The collision energy was $15 \mathrm{eV}$ for all the transitions and argon was used as the collision gas with a collision cell pressure of 1.2 mTorr.

\section{Quantitation of $0^{6}$-POB-dGuo by Liquid Chromatography-Nanoelectrospray lonization- High Resolution Tandem Mass Spectrometry (LC-NSI-HRMS/MS)}

The remaining sample after LC-ESI-MS/MS quantitation of POB-DNA adducts was subjected to further column purification for quantitation of $O^{6}$-POB-dGuo using LC-NSIHRMS/MS. Purification was performed on an Agilent 1100 capillary HPLC system with a $250 \mathrm{~mm} \times 0.5 \mathrm{~mm}$ Luna $5 \mu \mathrm{m} \mathrm{C18}$ column (Phenomenex, Torrance, CA) with a gradient from 5 to $90 \%$ of methanol in $5 \mathrm{mM} \mathrm{NH}_{4} \mathrm{OAc}$ in $35 \mathrm{~min}$, followed by $100 \%$ methanol wash for $5 \mathrm{~min}$, and then returned to $5 \%$ methanol for re-equilibration for $8 \mathrm{~min}$ at a flow rate of $10 \mu \mathrm{L} / \mathrm{min}$. The column was held at room temperature and the UV wavelength for detection was set at $254 \mathrm{~nm}$. Phenol was spiked into the samples to a final concentration of $3 \mu \mathrm{g} / \mathrm{mL}$ and co-injected as a UV marker $\left(t_{\mathrm{R}}=\sim 27.6 \mathrm{~min}\right.$ ) since it eluted just before $O^{6}$-POB-dGuo $\left(t_{\mathrm{R}}=\sim 28.2 \mathrm{~min}\right)$. The collection window began immediately after the phenol peak and before another inherent impurity peak from the DNA sample itself $\left(t_{\mathrm{R}}=\sim 28.9 \mathrm{~min}\right)$. The collected faction was concentrated to dryness and stored at $-20{ }^{\circ} \mathrm{C}$ until further quantitation.

The residue was re-dissolved in $20 \mu \mathrm{L} \mathrm{H}_{2} \mathrm{O}$ immediately before analysis and $8 \mu \mathrm{L}$ was injected for $O^{6}$-POB-dGuo quantitation using LC-NSI-HRMS/MS with accurate mass detection. A nanoHPLC column (75 $\mu \mathrm{m}$ ID, $360 \mu \mathrm{m}$ OD, $17 \mathrm{~cm}$ length, and $15 \mu \mathrm{m}$ orifice) packed with Synergi Hydro-RP bonded separation media (Phenomenex, Torrance, CA) in a commercially available fused silica emitter (New Objective, Woburn, MA) was installed on a Dionex UltiMate 3000 RSLCnano HPLC system coupled to an Orbitrap Fusion Tribrid Mass Spectrometer (Thermo Scientific, San Jose, CA) for sample separation and quantitation. The $8 \mu \mathrm{L}$ sample was first loaded onto a Symmetry C18 trap column (180 
$\mu \mathrm{m} \times 20 \mathrm{~mm}, 5 \mu \mathrm{m}$, Waters, Milford, MA) with $98 \%$ of $5 \mathrm{mM} \mathrm{NH}_{4} \mathrm{OAc}$ and $2 \% \mathrm{CH}_{3} \mathrm{CN}$ at a flow rate of $10 \mu \mathrm{L} / \mathrm{min}$ for $3 \mathrm{~min}$. Then the trapping valve was flipped so that the trap column was connected to the nanoHPLC column and back-flushed by a gradient from 2 to $30 \% \mathrm{CH}_{3} \mathrm{CN}$ in $5 \mathrm{mM} \mathrm{NH}_{4} \mathrm{OAc}$ at a flow rate of $300 \mathrm{~nL} / \mathrm{min}$ in $25 \mathrm{~min}$, followed by $50 \%$ $\mathrm{CH}_{3} \mathrm{CN}$ wash for $1 \mathrm{~min}$ and returned to $2 \% \mathrm{CH}_{3} \mathrm{CN}$ for re-equilibration for $10 \mathrm{~min}$. The following ion transitions were monitored with accurate mass extracted: $m / z 415.2[\mathrm{M}+\mathrm{H}]^{+}$ to $\mathrm{m} / z$ 148.0757 [POB] $]^{+}$and $152.0567[\mathrm{Gua}+\mathrm{H}]^{+}$for $O^{6}-\mathrm{POB}-\mathrm{dGuo}$, and $\mathrm{m} / z 419.2[\mathrm{M}$

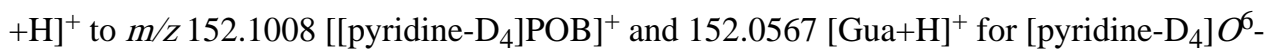
POB-dGuo. The precursor ions were isolated by a quadrupole with an isolation width of $\mathrm{m} / \mathrm{z}$ 1.5 , fragmented by high-energy collision dissociation (HCD) at 20\% collision energy and the resulting spectra detected by the Orbitrap detector with a resolution of 120,000. The ion source was operated in positive ion mode with a spray voltage of $2200 \mathrm{~V}$ and the ion transfer tube at $300{ }^{\circ} \mathrm{C}$. Peak integration was performed at $15 \mathrm{ppm}$ mass tolerance due to the coalescence effect ${ }^{26}$ caused by the close masses of $[\mathrm{Gua}+\mathrm{H}]^{+}$and [[pyridine- $\left.\left.\mathrm{D}_{4}\right] \mathrm{POB}\right]^{+}$ and the relatively high internal standard signal.

\section{Method Development and Validation}

To determine the precision and accuracy for $O^{6}$-POB-dGuo quantitation by LC-NSIHRMS/MS and validate the assay, $0.1,0.5,1$ and 5 fmol of $O^{6}$-POB-dGuo were spiked into $0.3 \mathrm{mg}$ of calf thymus DNA in succinate buffer with $200 \mathrm{fmol}$ of [pyridine- $\mathrm{D}_{4}$ ] $O^{6}$-POB$\mathrm{dGuo}$ as internal standard and subjected to the sample preparation procedures as described above including the HPLC column purification. Three spiked samples at each concentration level were prepared and analyzed by LC-NSI-HRMS/MS. The concentration was calculated using a calibration curve constructed by varying the concentration of $O^{6}$-POB-dGuo (6.5 422 amol on-column) and keeping the concentration of [pyridine- $\left.\mathrm{D}_{4}\right] O^{6}$-POB-dGuo constant (7.5 fmol on-column). The limit of detection (LOD) was determined with standard solutions of $O^{6}$-POB-dGuo. The limit of quantitation (LOQ) was determined by the lowest spiked level that produced a coefficient of variation (CV) of less than $10 \%$.

\section{Statistical Analyses}

The $t$-test was used for all comparisons between individual treatment groups. The difference between the additive effect of $(R)$-NNN and $(S)$-NNN versus racemic NNN was assessed using the $Z$-test. The mean and standard deviation for the additive effect were obtained by adding the means and variances from $(S)$ - and $(R)$-NNN groups, and then this was compared to the racemic NNN group. All tests were conducted at 5\% level of significance and the twotailed $p$-values were calculated.

\section{Results}

\section{Method Characterization}

The concentration range for the calibration curve and validation experiments were chosen to cover the range of $O^{6}$-POB-dGuo levels found in the rat tissue DNA samples. The calibration curve for $O^{6}$-POB-dGuo showed good linearity within the low concentration range $\left(R^{2}=0.9992\right.$, Figure $\left.3 \mathrm{~A}\right)$. The assay precision at all spiked levels was within $10 \% \mathrm{CV}$ (Table 2$)$ and good linearity was observed across the tested concentration range $\left(R^{2}=0.9988\right.$, 
Figure 3B). The assay accuracy was calculated as a percentage of added $O^{6}$-POB-dGuo and the average accuracy was $102 \% \pm 9 \%(n=4$, Table 2$)$. Since there was virtually no observable background noise with accurate mass detection, signal-to-noise ratio was not used to measure the limit of detection. Instead, the LOD was estimated by the lowest concentration on the linear calibration curve, which was $6.5 \mathrm{amol}$ from the standard solution. The LOQ was estimated by the lowest spiked level in the validation experiment that produced a CV less than $10 \%$, which was 100 amol in DNA samples.

\section{Quantitation of $O^{6}$-POB-dGuo in esophageal and oral mucosa}

Typical extracted ion chromatograms for the $O^{6}$-POB-dGuo quantitation using LC-ESIMS/MS and LC-NSI-HRMS/MS are shown in Figure 4. The adduct $O^{6}$-POB-dGuo from 7 ppm $(R)$-NNN-treated rat esophageal mucosa was not detectable using the low resolution, nominal mass MS/MS method (Fig. 4A) but produced a clear peak coeluting with the internal standard when using the high resolution, accurate mass MS/MS method (Fig. 4C). For the highest dosage group - $56 \mathrm{ppm}$ racemic NNN, the $O^{6}$-POB-dGuo was only slightly above the LC-ESI-MS/MS limit of detection (Fig. 4B) but was easily quantifiable when using the LC-NSI-HRMS/MS method (Fig. 4D).

$O^{6}$-POB-dGuo was successfully detected and quantified in rat esophageal and oral mucosa DNA in all treatment groups by LC-NSI-HRMS/MS. The $O^{6}$-POB-dGuo levels showed linear dose-responsive relationships for both esophageal and oral mucosa (Figure 5). In esophagus, $(S)$-NNN treatment produced slightly more $O^{6}$-POB-dGuo than $(R)$-NNN but the difference was not significant $(p>0.05)$ except for the median dosage level $(p=\mathbf{0 . 0 4})$. Interestingly, racemic NNN produced significantly more $O^{6}$-POB-dGuo $(61 \%$ and $31 \%$ respectively) than the additive sum of the two enantiomers at the low and median dosage levels $(p<0.05$, Table 3A). However, the high dosage level showed no evidence for synergism, indicating the synergistic effect in $O^{6}$-POB-dGuo formation is more pronounced at lower doses. The $56 \mathrm{ppm}$ racemic NNN group generated a slightly lower $O^{6}$-POB-dGuo level than the additive amounts, but the difference was not significant $(p=0.469)$. Overall $O^{6}$-POB-dGuo levels in rat oral mucosa were 3- to 5-fold lower than esophageal mucosa. $(S)$-NNN treatment produced significantly more $O^{6}$-POB-dGuo than $(R)$-NNN for the low and median dosage levels $(p<0.05)$. For the high dosage level, the adduct level from $(S)$ NNN was also higher than $(R)$-NNN but the difference was not significant $(p=0.103$ ). However, there was no significant difference between the $O^{6}$-POB-dGuo level from racemic NNN and the additive sum of the corresponding enantiomers at all three dosage levels, showing no synergism in $O^{6}$-POB-dGuo formation from oral mucosa (Table 3B).

\section{Quantitation of $0^{6}-\mathrm{POB}-\mathrm{dGuo}$ in other tissues}

$O^{6}$-POB-dGuo was detected and quantified in most of the nasal respiratory and olfactory mucosa samples from treated rats (23 and 16 out of 27 samples, respectively) using LC-ESIMS/MS. The results are summarized in Table 4. Since the adduct levels in some lower level groups were below the limit of detection on the triple quadrupole mass spectrometer, we were not able to obtain the statistical mean values and the standard deviations for these groups. Instead, results from single samples or the averages of two samples are reported (Table 4). We were only able to compare the racemic NNN groups with the additive sum of 
the corresponding enantiomers from nasal respiratory mucosa for the median and high dosage levels. The $O^{6}$-POB-dGuo level from racemic NNN was slightly lower than the additive sum for both median and high dosage levels (Table 4A). $O^{6}$-POB-dGuo was detected in two lung samples from the $28 \mathrm{ppm}$ racemic NNN treated group $(3 \mathrm{fmol} / \mathrm{mg}$ DNA, $n=2, \mathrm{LOD}=3 \mathrm{fmol} / \mathrm{mg}$ DNA) and three lung samples from the $56 \mathrm{ppm}$ racemic NNN treated group $(6 \pm 1 \mathrm{fmol} / \mathrm{mg}$ DNA, $n=3)$. $O^{6}$-POB-dGuo was not detected in any of the liver DNA samples (LOD $=3 \mathrm{fmol} / \mathrm{mg}$ DNA).

\section{Quantitation of other POB-DNA adducts}

Levels of other POB-DNA adducts are summarized in Table S1-S6 in the Supporting Information. The current study reproduced our previous results. ${ }^{8,} 9,11(S)$-NNN produced 3 to 5-fold more total POB-DNA adducts in esophagus, oral cavity and liver; while $(R)$-NNN produced 2 to 5 -fold more in nasal respiratory mucosa, nasal olfactory mucosa and lung. 7POB-Gua and $O^{2}$-POB-dThd were the major POB-DNA adducts in all the tissues, accounting for more than $95 \%$ of the total POB-DNA adducts in each tissue. No synergistic effect was found in either 7-POB-Gua or $O^{2}$-POB-dThd levels. Instead, an additive effect was observed for most treatment levels in most tissues, except for the highest dosage groups of lung and oral mucosa, where the racemic NNN groups produced lower levels than the additive sum. This may be due to the saturation of P450 enzymes or a possible antagonism effect under high dosage conditions. We were able to quantify $O^{2}$-POB-Cyt in nasal respiratory mucosa, nasal olfactory mucosa and lung in all treatment groups at three dosage levels, and an additive effect was also found for $O^{2}$-POB-Cyt in the above three tissues, except that the highest dosage level of lung showed an antagonistic effect (Tables S4-S6). In esophageal mucosa, oral mucosa and liver, $O^{2}$-POB-Cyt was only detected and quantified in 15,16 and 2 out of 27 samples, respectively (Table S1-S3). Due to its low quantity and the inability to obtain the statistical mean values from all treatment groups, we were not able to compare and evaluate the synergistic effect of $O^{2}$-POB-Cyt in these three tissues.

\section{Discussion}

Quantitation of $O^{6}$-POB-dGuo (4) from low ppm NNN-treated rat tissues was initially carried out by LC-ESI-MS/MS on a triple quadrupole mass spectrometer; LODs of $0.6 \mathrm{fmol}$ for pure standard and $3 \mathrm{fmol}$ for rat DNA samples were achieved. Using this method, we were able to quantify the levels of $O^{6}$-POB-dGuo from most of the nasal respiratory and olfactory mucosa samples ( 23 and 16 out of 27 samples, respectively). However, $O^{6}$-POBdGuo was only detected in the esophageal and oral mucosa from several $28 \mathrm{ppm}$ and $56 \mathrm{ppm}$ racemic NNN treated rats. Since these were the major target tissues in which synergistic effects were observed for NNN tumorigenicity, we needed to develop a more sensitive method. Therefore, we used LC-NSI-HRMS/MS. Compared to the low resolution method, the high resolution method greatly reduced the background noise from the sample matrix by using accurate mass detection and maximized the signal-to-noise ratio for quantitation from complex DNA samples. In addition to transitioning from low to high resolution mass spectrometry, the LC flow rate was reduced from $10 \mu \mathrm{L} / \mathrm{min}$ on a $0.5 \mathrm{~mm} \mathrm{LC}$ column to 300 $\mathrm{nL} / \mathrm{min}$ on a hand-packed nanoHPLC column (ID: $75 \mu \mathrm{m}$ ) to accommodate the NSI technique. Compared to the capillary flow ESI, NSI greatly increased the ionization and ion 
transport efficiency resulting in much greater sensitivity. ${ }^{27}$ In a previous attempt using NSI and a high resolution orbital trap (Orbitrap Velos) mass spectrometer, $O^{6}$-POB-dGuo was detected in $14 \mathrm{ppm}(R)$-NNN and $(S)$-NNN-treated rat nasal respiratory mucosa and $14 \mathrm{ppm}$ (S)-NNN-treated rat esophageal mucosa. ${ }^{11}$ However, accurate quantitation was not achieved due to inadequate sensitivity. A newer generation, high resolution orbital trap (Orbitrap Fusion Tribrid) mass spectrometer equipped with a quadrupole filter was used in place of the earlier LTQ Orbitrap Velos instrument, with more efficient precursor ion isolation using the quadrupole filter for the $\mathrm{MS}^{2}$ fragmentation. Also, the DNA samples were subjected to LC purification prior to injection onto the nano-LC column for MS analysis. This additional purification step further reduced sample matrix suppression and eliminated coeluting peaks that interfered with quantitation. Overall, the newly developed LC-NSI-HRMS/MS method allowed the quantitation of ultra trace levels of $O^{6}$-POB-dGuo from low-dosage NNNtreated rats with a LOD of 6.5 amol for diluted standard and 100 amol for spiked calf thymus DNA samples, which is about a 100-fold improvement over the LC-ESI-MS/MS method.

$O^{6}$-POB-dGuo is present at lower levels relative to other identified POB-DNA adducts in NNN treated rats as shown by our previous studies. ${ }^{8,9,11}$ It is also the least abundant of identified adducts upon reaction of calf thymus DNA with the pyridyloxobutylating agent NNKOAc in vitro, ${ }^{23}$ indicating the relatively low reactivity of the $O^{6}$ guanine position compared to other nucleophilic sites. Besides the low yield, $O^{6}$-POB-dGuo is also a substrate for $O^{6}$-alkylguanine-DNA alkyltransferase (AGT), which repairs this modification by transferring the $O^{6}$-alkyl group to its cysteine residue resulting in inactivation and degradation of the protein. ${ }^{22,} 28$ In the current study, $O^{6}$-POB-dGuo only accounted for $\leq 1 \%$ of total POB-DNA adducts identified but is apparently the most mutagenic. ${ }^{14} O^{6}$-POB-dGuo induces $\mathrm{G}$ to $\mathrm{A}$ transition mutations in $E$. coli, and $\mathrm{G}$ to $\mathrm{A}$ transitions, $\mathrm{G}$ to $\mathrm{T}$ transversions, base deletion and remote mutations in human HEK-293 cells. ${ }^{14}$ In addition, multiple studies have shown that $O^{6}$-alkylguanine lesions formed from both endogenous and exogenous sources can induce mainly $\mathrm{G}$ to A mutations and are believed to be highly mutagenic. ${ }^{29}$ However, there are few studies on the mutagenicity of the other three POB-DNA adducts. One study showed a preference for insertion of dThd opposite the $O^{2}$-POB-dThd adduct during in vitro PCR amplification. ${ }^{30}$ So far as we are aware, there is no direct side-by-side or quantitative comparison of the mutagenicity of the four identified POB-DNA adducts.

In our previous tumorigenicity study, ${ }^{3}$ all rats treated with $14 \mathrm{ppm}(S)$-NNN had oral cavity tumors and esophageal tumors, while $14 \mathrm{ppm}(R)$-NNN was only weakly carcinogenic. Interestingly, the number of tumors per rat from $28 \mathrm{ppm}$ racemic NNN treatment was significantly higher than the additive effect of the two individual enantiomers, suggesting that the weak carcinogen $(R)$-NNN can synergistically enhance the carcinogenicity of $(S)$ NNN. In the current study, three dosage levels were employed to provide dose-dependent assessment of a possible synergistic effect in DNA adduct formation. As shown in Table 3A, the low and median dosage levels showed a synergistic effect in the formation of $O^{6}$-POBdGuo in esophagus, suggesting that the least abundant but highly mutagenic $O^{6}$-POB-dGuo could potentially play an important role in the synergistic effect found in NNN induced esophageal tumors in rats. However, the synergistic effect observed in tumor formation is much more pronounced than that in the $O^{6}$-POB-dGuo formation, indicating that there may 
be downstream biological processes other than DNA adduct formation responsible for the synergism. The observed synergistic effect in $O^{6}$-POB-dGuo formation was clearly dosedependent, with the low dosage groups exhibiting the most significant synergism. This effect became less evident at the median dosage level, and no synergistic effect was observed for the high dosage groups. This may be due to oversaturation of the P450 enzymes under high dosage conditions.

One possible hypothesis for the observed synergistic effect in $O^{6}$-POB-dGuo formation involves the repair efficiency of $O^{6}$-POB-dGuo by AGTs. Aldehydes can inhibit the repair activity of AGTs by reacting with the cysteine residue in the active site and thus function as co-carcinogenic agents with alkylating compounds. ${ }^{31,32} 5^{\prime}$-Hydroxylation of NNN primarily generates the hydrolysis product lactol 17 (Scheme S1, Supporting Information), which is in equilibrium with a hydroxy aldehyde $\mathbf{1 6},{ }^{1}$ which can potentially inhibit the repair pathway and cause persistence of this DNA lesion. Moreover, it is possible that the diazohydroxide intermediate $\mathbf{1 1}$ or diazonium ion $\mathbf{1 2}$ can lose nitrogen to form an aldehyde carbocation 13 that can undergo E1 elimination and rearrangement to produce an $\alpha, \beta$ unsaturated aldehyde $\mathbf{1 5}$ which may be a more potent inhibitor. ${ }^{31,32}(R)$-NNN is known to be metabolized equally through $2^{\prime}$ - and $5^{\prime}$-hydroxylation, while $(S)$-NNN is preferentially $2^{\prime}$-hydroxylated in cultured rat esophagus. ${ }^{10}$ Therefore, the aldehyde metabolites from extensive $5^{\prime}$-hydroxylation of $(R)$-NNN in esophagus may suppress the repair of $O^{6}$-POBdGuo when dosing together with ( $S$ )-NNN and synergistically enhance the overall carcinogenicity. This inhibitory effect may also be important in explaining the relatively high levels of $O^{6}$-POB-dGuo in $(R)$-NNN-treated rats, which was only slightly lower than that from $(S)$-NNN $(P>0.05)$; while more than a 3 -fold difference was observed between the two enantiomers for other POB-DNA adducts.

In contrast to esophageal mucosa, an additive rather than synergistic effect in $O^{6}$-POB-dGuo formation was observed in oral cavity DNA at all three dosage levels. Unlike the uniform mucosa layer collected from the esophagus, oral mucosa was collected from both buccal sides, hard palate, soft palate and the top layer of the tongue. The relatively non-uniform tissue distribution adds more complexity to the adduct analysis. Oral bacteria can be another factor in the complexity. Also, a significant number of tumors were found in the back of the oral cavity closer to the pharynx, while in this study the DNA adducts from the entire oral mucosa were measured together. Therefore, the collective oral mucosa adduct levels may not accurately represent the exact levels where tumors were found.

Nasal cavity is also an NNN target tissue and tumors have been generated by a number of administration routes. ${ }^{1}$ In our previous tumorigenicity study where NNN was supplied in the drinking water, tumors were also formed in nasal respiratory epithelium and olfactory mucosa in 6 of $20(S)$-NNN-treated rats, 4 of $24(R)$-NNN-treated rats, and 3 of 11 racemic NNN-treated rats. ${ }^{3}$ Thus the tumor formation in the nasal cavity does not mirror the stark differences between $(S)$-NNN, $(R)$-NNN and racemic NNN we observed in the oral and esophageal mucosa. Therefore, we didn't attempt to quantify the $O^{6}$-POB-dGuo from nasal cavity by the sensitive LC-NSI-HRMS/MS method. Due to the extensive metabolism that takes place in the nasal cavity, the overall POB-DNA adducts as well as the $O^{6}$-POB-dGuo levels were among the highest of all tissues and thus were quantified in some higher level 
treatment groups by the LC-ESI-MS/MS method (Table 4). No synergism was found in $O^{6}$ POB-dGuo levels in the nasal respiratory mucosa for the median or high dosage levels, which was consistent with the tumorigenicity study.

Compared to $O^{6}$-alkylguanine, there are very few studies on the mutagenic properties of $O^{2}$ alkylated cytosine and thymidine. One study mentioned above showed low fidelity bypass of $O^{2}$-POB-dT. ${ }^{30}$ The mutagenicity of 7-POB-Gua is also unknown but other 7-alkylated guanines such as those formed from aflatoxin $\mathrm{B}_{1}$ are mutagenic, causing $\mathrm{G}$ to $\mathrm{T}$ mutations. ${ }^{33}, 34 N^{7}$-Alkylated guanine adducts are susceptible to depurination due to the destabilized $\mathrm{N}$-glycosidic bond or from DNA-glycosylase repair yielding potentially mutagenic apurinic (AP) sites; mutagenic imidazole ring-opened formamidopyrimidine lesions (alkyl-FAPy) can also be formed. ${ }^{35,} 36$ Strikingly high levels of 7-POB-Gua relative to $O^{2}$-POB-dThd were observed in esophageal and oral mucosa (45-65\%) compared to other tissues (20 - 30\%), suggesting a possible role of 7-POB-Gua in carcinogenesis in these two target tissues. Possible reasons for the abundance of 7-POB-Gua in these tissues may be related to differences in repair mechanisms or cellular turnover rate, but this is currently not well understood.

In summary, we have developed a novel LC-NSI-HRMS/MS method for quantitation of ultra-trace levels of $O^{6}$-POB-dGuo from low-dose NNN-treated rats with 100-fold improvement in sensitivity compared to the low-resolution LC-ESI-MS/MS method. Our results have shown that this highly mutagenic POB-DNA adduct may contribute in part to the synergism observed in the induction of esophageal tumors by NNN in rats.

\section{Supplementary Material}

Refer to Web version on PubMed Central for supplementary material.

\section{Acknowledgments}

The authors thank Erik Carlson for help with rat handling and animal care, Erik Carlson, Adam Zarth, Ben Ransom, Makenzie Pillsbury and Dr. Silvia Balbo for help with rat sacrifice and tissue collection, Dr. Chap T. Le for advice on statistical analysis, and Bob Carlson for editorial assistance. Jing Yang thanks Adam Zarth for helpful discussions and suggestions, and Xun Ming for assistance in the operation of mass spectrometers.

Funding:

This study was supported by grant R01-CA081301 from the National Cancer Institute. Mass spectrometry was carried out in the Analytical Biochemistry Shared Resource of the Masonic Cancer Center, University of Minnesota, funded in part by Cancer Center Support Grant CA-77598.

\section{References}

1. Hecht SS. Biochemistry, biology, and carcinogenicity of tobacco-specific $N$-nitrosamines. Chem. Res. Toxicol. 1998; 11:559-603. [PubMed: 9625726]

2. International Agency for Research on Cancer. IARC Monographs on the Evaluation of Carcinogenic Risks to Humans. Lyon, France: IARC; 2007. Smokeless Tobacco and Some Tobacco-specific $N$ Nitrosamines.

3. Balbo S, James-Yi S, Johnson CS, O'Sullivan MG, Stepanov I, Wang MY, Bandyopadhyay D, Kassie F, Carmella S, Upadhyaya P, Hecht SS. (S)- $N^{\prime}$-Nitrosonornicotine, a constituent of smokeless 
tobacco, is a powerful oral cavity carcinogen in rats. Carcinogenesis. 2013; 34:2178-2183. [PubMed: 23671129]

4. Brittebo EB, Castonguay A, Furuya K, Hecht SS. Metabolism of tobacco-specific nitrosamines by cultured rat nasal mucosa. Cancer Res. 1983; 43:4343-4348. [PubMed: 6871868]

5. Murphy SE, Heiblum R, Trushin N. Comparative metabolism of $N$-nitrosonornicotine and 4(methylnitrosamino)-1-(3-pyridyl)-1-butanone by cultured F344 rat oral tissue and esophagus. Cancer Res. 1990; 50:4685-4691. [PubMed: 2369743]

6. Hecht SS, Spratt TE, Trushin N. Evidence for 4-(3-pyridyl)-4-oxobutylation of DNA in F344 rats treated with the tobacco specific nitrosamines 4-(methylnitrosamino)-1-(3-pyridyl)-1-butanone and $N$-nitrosonornicotine. Carcinogenesis. 1988; 9:161-165. [PubMed: 3335041]

7. Trushin N, Rivenson A, Hecht SS. Evidence supporting the role of DNA pyridyloxobutylation in rat nasal carcinogenesis by tobacco-specific nitrosamines. Cancer Res. 1994; 54:1205-1211. [PubMed: 8118807]

8. Lao YB, Yu NX, Kassie F, Villalta PW, Hecht SS. Analysis of pyridyloxobutyl DNA adducts in F344 rats chronically treated with $(R)$ - and $(S)$ - $N^{\prime}$-nitrosonornicotine. Chem. Res. Toxicol. 2007; 20:246-256. [PubMed: 17305408]

9. Zhang SY, Wang MY, Villalta PW, Lindgren BR, Lao YB, Hecht SS. Quantitation of Pyridyloxobutyl DNA Adducts in Nasal and Oral Mucosa of Rats Treated Chronically with Enantiomers of $N^{\prime}$-Nitrosonornicotine. Chem. Res. Toxicol. 2009; 22:949-956. [PubMed: 19405515]

10. McIntee EJ, Hecht SS. Metabolism of $N$ '-nitrosonornicotine enantiomers by cultured rat esophagus and in vivo in rats. Chem. Res. Toxicol. 2000; 13:192-199. [PubMed: 10725116]

11. Zhao LJ, Balbo S, Wang MY, Upadhyaya P, Khariwala SS, Villalta PW, Hecht SS. Quantitation of Pyridyloxobutyl-DNA Adducts in Tissues of Rats Treated Chronically with $(R)$ - or $(S)$ - $N^{\prime}$ Nitrosonornicotine (NNN) in a Carcinogenicity Study. Chem. Res. Toxicol. 2013; 26:1526-1535. [PubMed: 24001146]

12. Woodside AM, Guengerich FP. Effect of the $O^{6}$ substituent on misincorporation kinetics catalyzed by DNA polymerases at $O^{6}$-methylguanine and $O^{6}$-benzylguanine. Biochemistry. 2002; 41:10271038. [PubMed: 11790127]

13. Pauly GT, Moschel RC. Mutagenesis by $O^{6}$-methyl-, $O^{6}$-ethyl-, and $O^{6}$-benzylguanine and $O^{4}$ methylthymine in human cells: Effects of $O^{6}$-alkylguanine-DNA alkyltransferase and mismatch repair. Chem. Res. Toxicol. 2001; 14:894-900. [PubMed: 11453737]

14. Pauly GT, Peterson LA, Moschel RC. Mutagenesis by $O^{6}$-[4-oxo-4-(3-pyridyl)butyl]guanine in Escherichia coli and human cells. Chem. Res. Toxicol. 2002; 15:165-169. [PubMed: 11849042]

15. Thomson NM, Kenney PM, Peterson LA. The pyridyloxobutyl DNA adduct, $O^{6}$-[4-oxo-4-(3pyridyl)butyl]guanine, is detected in tissues from 4-(methylnitrosamino)-1-(3-pyridyl)-1-butanonetreated A/J mice. Chem. Res. Toxicol. 2003; 16:1-6. [PubMed: 12693024]

16. Thomson NM, Mijal RS, Ziegel R, Fleischer NL, Pegg AE, Tretyakova NY, Peterson LA. Development of a quantitative liquid chromatography/electrospray mass spectrometric assay for a mutagenic tobacco specific nitrosamine-derived DNA adduct, $O^{6}$-[4-oxo-4-(3-pyridyl)butyl]-2'deoxyguanosine. Chem. Res. Toxicol. 2004; 17:1600-1606. [PubMed: 15606135]

17. Lao YB, Villalta PW, Sturla SJ, Wang MY, Hecht SS. Quantitation of pyridyloxobutyl DNA adducts of tobacco-specific nitrosamines in rat tissue DNA by high-performance liquid chromatography-electrospray ionization-tandem mass spectrometry. Chem. Res. Toxicol. 2006; 19:674-682. [PubMed: 16696570]

18. Zhang SY, Wang MY, Villalta PW, Lindgren BR, Upadhyaya P, Lao YB, Hecht SS. Analysis of Pyridyloxobutyl and Pyridylhydroxybutyl DNA Adducts in Extrahepatic Tissues of F344 Rats Treated Chronically with 4-(Methylnitrosamino)-1-(3-pyridyl)-1-butanone and Enantiomers of 4(Methylnitrosamino)-1-(3-pyridyl)-1-butanol. Chem. Res. Toxicol. 2009; 22:926-936. [PubMed: 19358518]

19. Hu MW, Bondinell WE, Hoffmann D. Chemical studies on tobacco smoke XXIII. Synthesis of carbon-14 labelled myosmine, nornicotine and $N^{\prime}$-nitrosonornicotine. J. Label. Compd. Radiopharm. 1974; 10:79-88. 
20. Seeman JI, Chavdarian CG, Secor HV. Synthesis of the enantiomers of nornicotine. J. Org. Chem. 1985; 50:5419-5421.

21. Wang MY, Cheng G, Sturla SJ, Shi YL, McIntee EJ, Villalta PW, Upadhyaya P, Hecht SS. Identification of adducts formed by pyridyloxobutylation of deoxyguanosine and DNA by 4(acetoxymethylnitrosamino)-1-(3-pyridyl)-1-butanone, a chemically activated form of tobacco specific carcinogens. Chem. Res. Toxicol. 2003; 16:616-626. [PubMed: 12755591]

22. Wang LJ, Spratt TE, Liu XK, Hecht SS, Pegg AE, Peterson LA. Pyridyloxobutyl adduct $O^{6}$-[4oxo-4-(3-pyridyl)butyl] guanine is present in 4-(acetoxymethylnitrosamino)-1-(3-pyridyl)-1butanone-treated DNA and is a substrate for $O^{6}$-alkylguanine-DNA alkyltransferase. Chem. Res. Toxicol. 1997; 10:562-567. [PubMed: 9168254]

23. Sturla SJ, Scott J, Lao YB, Hecht SS, Villalta PW. Mass spectrometric analysis of relative levels of pyridyloxobutylation adducts formed in the reaction of DNA with a chemically activated form of the tobacco-specific carcinogen 4-(methylnitrosamino)-1-(3-pyridyl)-1-butanone. Chem. Res. Toxicol. 2005; 18:1048-1055. [PubMed: 15962940]

24. Wang MY, Yu NX, Chen L, Villalta PW, Hochalter JB, Hecht SS. Identification of an acetaldehyde adduct in human liver DNA and quantitation as $N^{2}$-ethyldeoxyguanosine. Chem. Res. Toxicol. 2006; 19:319-324. [PubMed: 16485909]

25. Gupta RC. Enhanced sensitivity of ${ }^{32} \mathrm{P}$-postlabeling analysis of aromatic carcinogen-DNA adducts. Cancer Res. 1985; 45:5656-5662. [PubMed: 4053037]

26. Gorshkov MV, Fornelli L, Tsybin YO. Observation of ion coalescence in Orbitrap Fourier transform mass spectrometry. Rapid Commun. Mass Spectrom. 2012; 26:1711-1717. [PubMed: 22730091]

27. Smith RD, Shen YF, Tang KQ. Ultrasensitive and quantitative analyses from combined separations-mass spectrometry for the characterization of proteomes. Accounts Chem. Res. 2004; 37:269-278.

28. Mijal RS, Thomson NM, Fleischer NL, Pauly GT, Moschel RC, Kanugula S, Fang QM, Pegg AE, Peterson LA. The repair of the tobacco specific nitrosamine derived adduct $O^{6}$-[4-oxo-4-(3pyridyl)butyl]guanine by $O^{6}$-alkylguanine-DNA alkyltransferase variants. Chem. Res. Toxicol. 2004; 17:424-434. [PubMed: 15025514]

29. Shrivastav N, Li DY, Essigmann JM. Chemical biology of mutagenesis and DNA repair: cellular responses to DNA alkylation. Carcinogenesis. 2010; 31:59-70. [PubMed: 19875697]

30. Gowda ASP, Krishnegowda G, Suo ZC, Amin S, Spratt TE. Low Fidelity Bypass of $O^{2}-(3-$ Pyridyl)-4-oxobutylthymine, the Most Persistent Bulky Adduct Produced by the Tobacco Specific Nitrosamine 4-(Methylnitrosamino)-1-(3-pyridyl)-1-butanone by Model DNA Polymerases. Chem. Res. Toxicol. 2012; 25:1195-1202. [PubMed: 22533615]

31. Krokan H, Grafstrom RC, Sundqvist K, Esterbauer H, Harris CC. Cytotoxicity, thiol depletion and inhibition of $O^{6}$-methylguanine-DNA methyltransferase by various aldehydes in cultured human bronchial fibroblasts. Carcinogenesis. 1985; 6:1755-1759. [PubMed: 4064250]

32. Grafstrom, RC.; Pegg, AE.; Harris, CC.; Sundqvist, K.; Krokan, H. $O^{6}$-methylguanine-DNA methyltransferase activity and aldehyde induced inhibition of $O^{6}$-methylguanine repair in human lung cells. In: Myrnes, B.; Krokan, H., editors. Repair of DNA lesions introduced by N-nitroso compounds. Olslo, Norway: Norwegian University Press; 1986. p. 154-175.

33. Bailey EA, Iyer RS, Stone MP, Harris TM, Essigmann JM. Mutational properties of the primary aflatoxin B $_{1}$-DNA adduct. Proc. Natl. Acad. Sci. U.S.A. 1996; 93:1535-1539. [PubMed: 8643667]

34. Smela ME, Hamm ML, Henderson PT, Harris CM, Harris TM, Essigmann JM. The aflatoxin $\mathrm{B}_{1}$ formamidopyrimidine adduct plays a major role in causing the types of mutations observed in human hepatocellular carcinoma. Proc. Natl. Acad. Sci. U.S.A. 2002; 99:6655-6660. [PubMed: 12011430]

35. Loeb LA, Preston BD. Mutagenesis by apurinic/apyrimidinic sites. Annu. Rev. Genet. 1986; 20:201-230. [PubMed: 3545059]

36. Boysen G, Pachkowski BF, Nakamura J, Swenberg JA. The formation and biological significance of N7-guanine adducts. Mutat. Res. Genet. Toxicol. Environ. Mutagen. 2009; 678:76-94. 


\section{Abbreviations}

NNN

NNK

POB-DNA adducts

$O^{6}$-POB-dGuo

$O^{2}$-POB-dThd

7-POB-dGuo

7-POB-Gua

$O^{2}$-POB-dCyd

$O^{2}$-POB-Cyt

LC-ESI-MS/MS

SRM

LC-NSI-HRMS/MS

EIC

AGT
$N^{\prime}$-nitrosonornicotine

4-(methylnitrosamino)-1-(3-pyridyl)-1-butane

4-(3-pyridyl)-4-oxobutyl-DNA adducts

$O^{6}$-[4-(3-pyridyl)-4-oxobut-1-yl]-2' -deoxyguanosine

$O^{2}$-[4-(3-pyridyl)-4-oxobut-1-yl]thymidine

7-[4-(3-pyridyl)-4-oxobut-1-yl]-2' -deoxyguanosine

7-[4-(3-pyridyl)-4-oxobut-1-yl]guanine

$O^{2}$-[4-(3-pyridyl)-4-oxobut-1-yl]-2'-deoxycytidine

$O^{2}$-[4-(3-pyridyl)-4-oxobut-1-yl]cytosine

liquid chromatography-electrospray ionization-tandem

mass spectrometry

selected reaction monitoring

liquid chromatography-nanoelectrospray ionization-high resolution tandem mass spectrometry

extracted ion chromatogram

$O^{6}$-alkylguanine-DNA alkyltransferase 


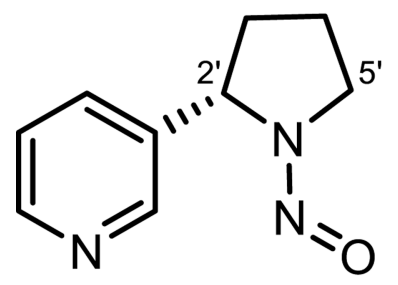

(S)-NNN (1)

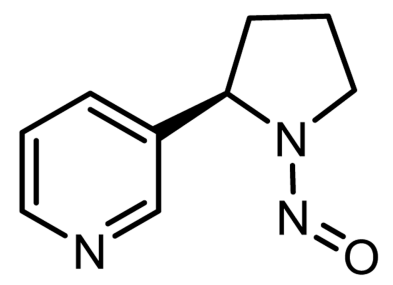

(R)-NNN (2)

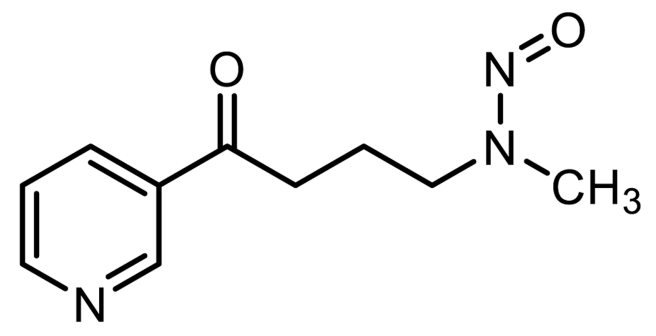

NNK (3)

Figure 1.

Structures of $(S)$-NNN (1), $(R)$-NNN (2) and NNK (3) 
<smiles>[R10][R6](=O)O[Na]</smiles>

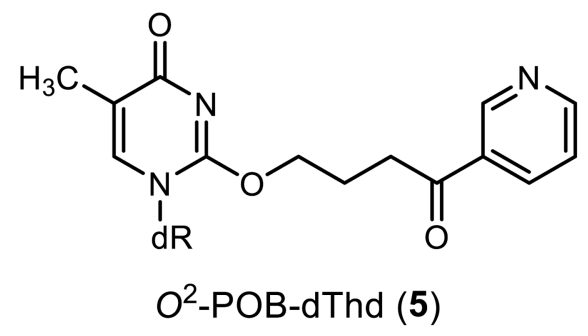<smiles></smiles>

7-POB-dGuo (6)<smiles>[R][n+]1ccc(N)nc1OCCCC(=O)c1cccnc1</smiles><smiles>Nc1nc2ncn(CCCC(=O)c3cccnc3)c2c(=O)[nH]1</smiles><smiles>Nc1ccnc(OCCCC(=O)c2cccnc2)n1</smiles>

Figure 2.

Structures of the POB-DNA adducts $\left(\mathbf{4}\right.$ - 9). $d R=2^{\prime}$-deoxyribose. 

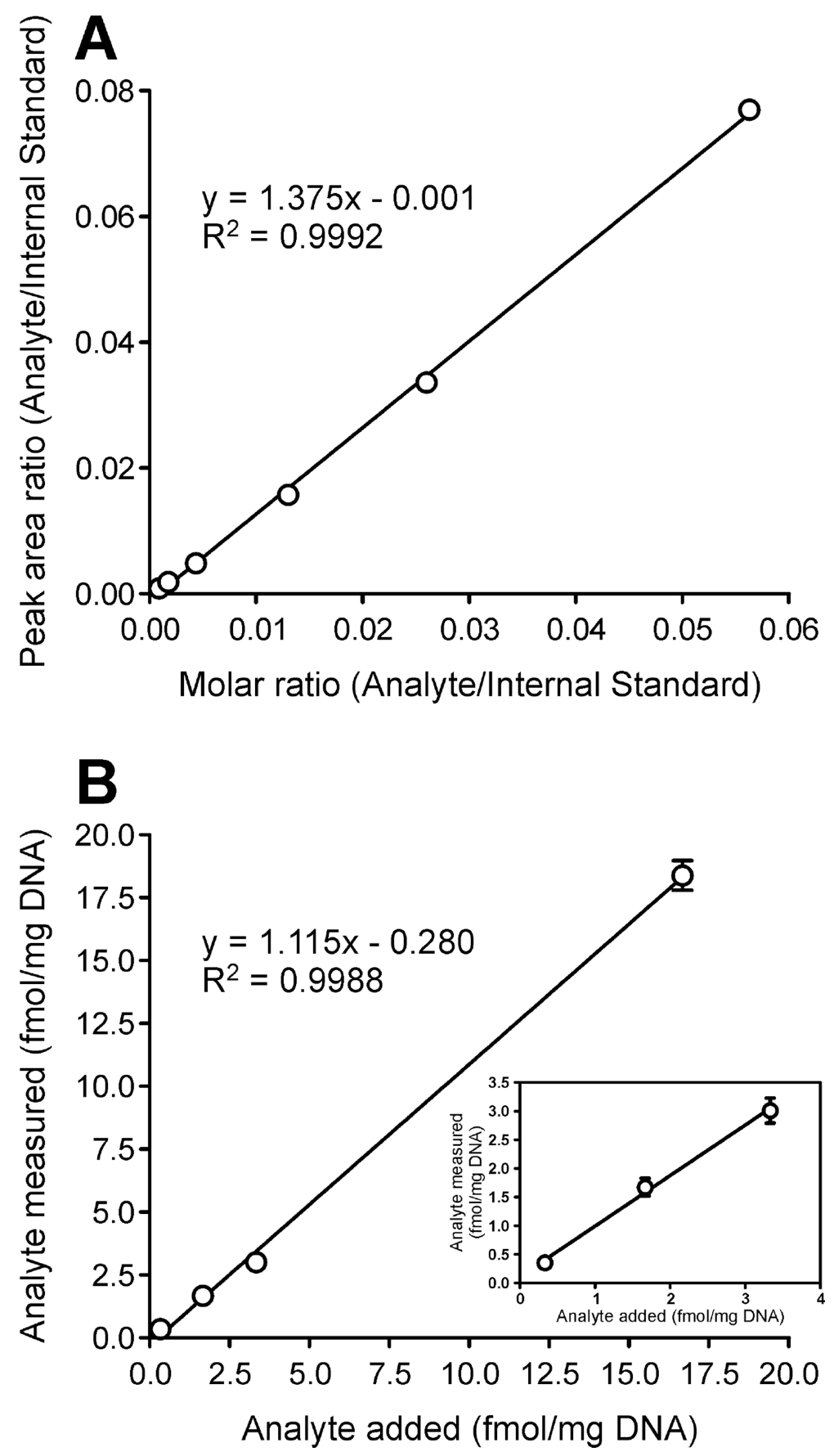

Figure 3.

Method characterization for $O^{6}$-POB-dGuo quantitation by LC-NSI-HRMS/MS. The analyte is $O^{6}$-POB-dGuo and the internal standard is [pyridine- $\left.\mathrm{D}_{4}\right] O^{6}$-POB-dGuo. (A) Calibration curve for $O^{6}$-POB-dGuo. The amount of [pyridine- $\mathrm{D}_{4}$ ] $O^{6}-\mathrm{POB}-\mathrm{dGuo}$ was maintained constant at $7.5 \mathrm{fmol}$ on-column, while the amount of $O^{6}$-POB-dGuo ranged from 6.5 to 422 amol on-column. (B) Relationship between added and measured $O^{6}$-POB-dGuo in $0.3 \mathrm{mg}$ calf thymus DNA. Each data point represents the average of three replicates. The error bar represents the standard deviation. 

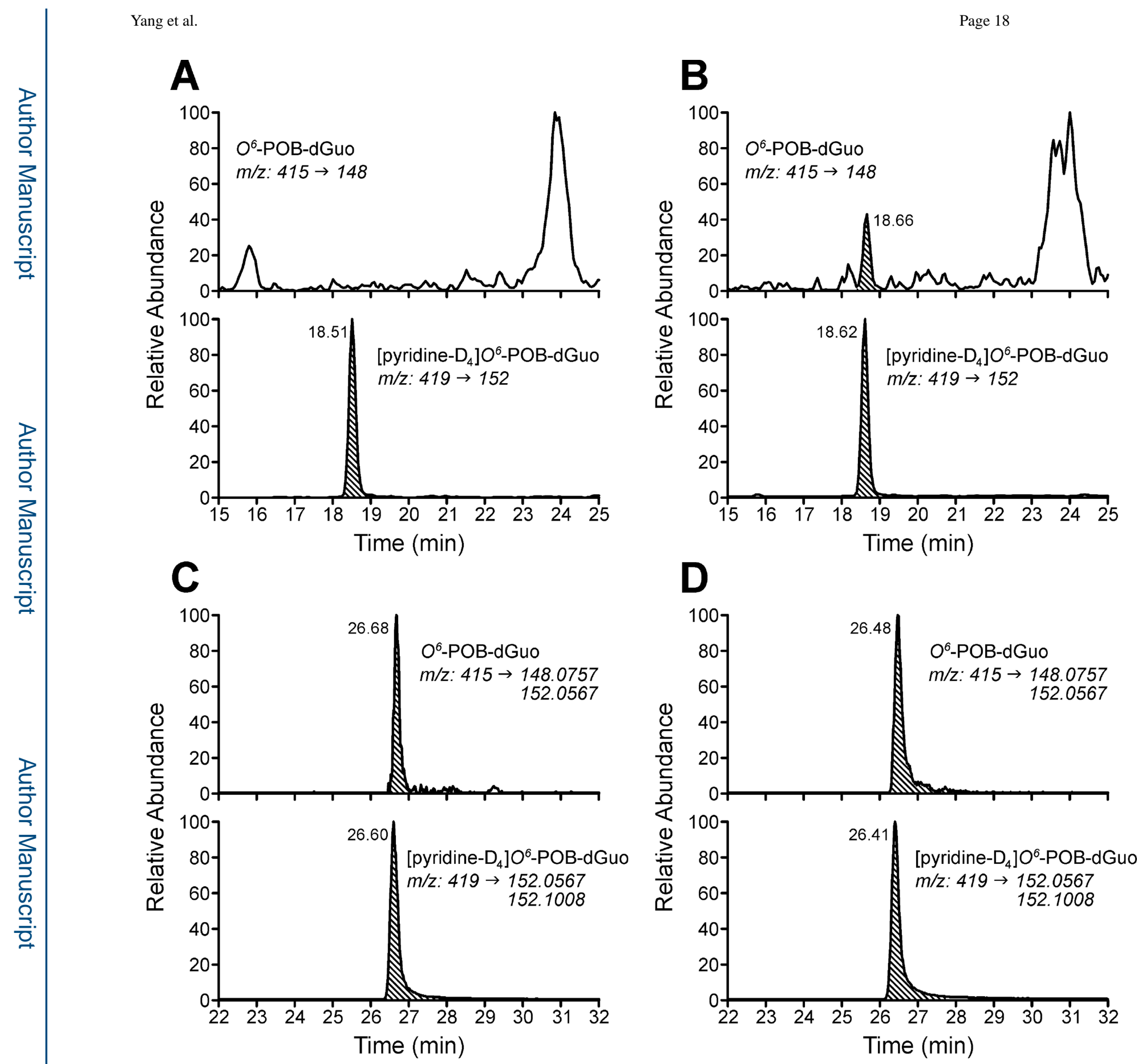

Figure 4.

Extracted ion chromatograms (EIC) for $O^{6}$-POB-dGuo from $7 \mathrm{ppm}(R)$-NNN-treated rat esophageal mucosa using LC-ESI-MS/MS (A) and LC-NSI-HRMS/MS (C); EIC for $O^{6}$ POB-dGuo from $56 \mathrm{ppm}$ racemic NNN-treated rat esophageal mucosa using LC-ESIMS/MS (B) and LC-NSI-HRMS/MS (D). For the LC-ESI-MS/MS method, the following ion transitions were monitored: $\mathrm{m} / z 415$ to 148 for $O^{6}$-POB-dGuo, and $m / z 419$ to 152 for the internal standard [pyridine- $\left.\mathrm{D}_{4}\right] O^{6}$-POB-dGuo. For the LC-NSI-HRMS/MS method, the following ion transitions were monitored with accurate mass extracted: $\mathrm{m} / \mathrm{z} 415$ to 148.0757 
and 152.0567 for $O^{6}$-POB-dGuo; $\mathrm{m} / \mathrm{Z} 419$ to 152.0567 and 152.1008 for [pyridine-- $\mathrm{D}_{4}$ ] $O^{6}$ POB-dGuo. 

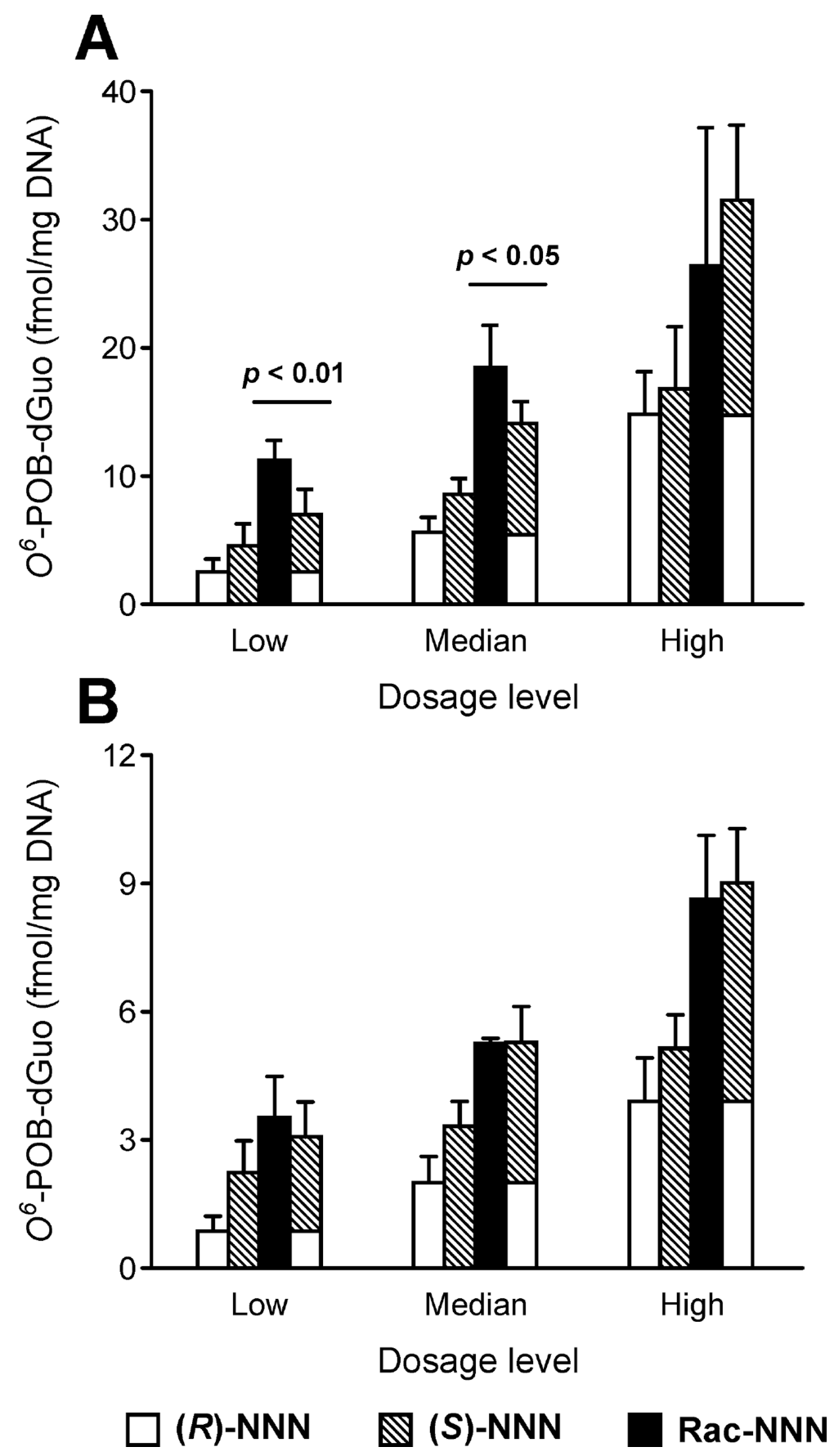

Figure 5.

Levels of $O^{6}$-POB-dGuo in (A) esophageal mucosa and (B) oral mucosa. Low dosage level: 7 ppm $(R)-\mathrm{NNN}, 7$ ppm $(S)-\mathrm{NNN}$ and 14 ppm racemic NNN; Median dosage level: 14 ppm $(R)-\mathrm{NNN}, 14 \mathrm{ppm}(S)-\mathrm{NNN}$ and $28 \mathrm{ppm}$ racemic NNN; High dosage level: $28 \mathrm{ppm}(R)-$ NNN, 28 ppm $(S)$-NNN and 56 ppm racemic NNN. Open bars represent $(R)$-NNN treated groups; Grey bars represent $(S)$-NNN groups; Black bars represent racemic NNN groups; the stacked bars represent the additive sum of the corresponding $(R)$-NNN and $(S)$-NNN 
treated groups. Each column is the average of three replicates and the error bars represent the standard deviations. 


\section{Table 1}

SRM Transitions for POB-DNA Adducts and Internal Standards

\begin{tabular}{|c|c|c|}
\hline POB-DNA adducts & $\begin{array}{l}\text { precursor ion } \\
\left([\mathrm{M}+\mathrm{H}]^{+}, m / z\right)\end{array}$ & $\begin{array}{l}\text { production } \\
(m / z)\end{array}$ \\
\hline$O^{2}$-POB-Cyt (9) & 259.1 & $148.1[\mathrm{POB}]^{+}$ \\
\hline [pyridine- $\left.\mathrm{D}_{4}\right] O^{2}$-POB-Cyt & 263.1 & 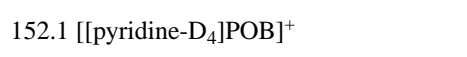 \\
\hline 7-POB-Gua (8) & 299.1 & $148.1[\mathrm{POB}]^{+}$ \\
\hline [pyridine- $\mathrm{D}_{4}$ ]7-POB-Gua & 303.1 & $152.1\left[\right.$ [pyridine- $\left.\left.\mathrm{D}_{4}\right] \mathrm{POB}\right]^{+}$and $[\mathrm{Gua}+\mathrm{H}]^{+}$ \\
\hline$O^{2}$-POB-dThd (5) & 390.1 & $148.1[\mathrm{POB}]^{+}$ \\
\hline [pyridine- $\left.\mathrm{D}_{4}\right] O^{2}$-POB-dThd & 394.1 & 152.1 [[pyridine- $\left.\left._{4}\right] \mathrm{POB}\right]^{+}$ \\
\hline$O^{6}$-POB-dGuo (4) & 415.1 & $148.1[\mathrm{POB}]^{+}$ \\
\hline [pyridine- $\left.\mathrm{D}_{4}\right] O^{6}$-POB-dGuo & 419.1 & $152.1\left[\left[\text { pyridine- } \mathrm{D}_{4}\right] \mathrm{POB}\right]^{+}$and $[\mathrm{Gua}+\mathrm{H}]^{+}$ \\
\hline
\end{tabular}




\section{Table 2}

Assay precision and accuracy for $O^{6}$-POB-dGuo quantitation by LC-NSI-HRMS/MS.

\begin{tabular}{cccc}
\hline $\begin{array}{c}\text { Added } \\
\text { (fmol) }\end{array}$ & $\begin{array}{c}\text { Measured } \\
\text { (fmol) }\end{array}$ & CV\% & Accuracy \\
\hline 0.1 & $0.106 \pm 0.008$ & $7 \%$ & $106 \%$ \\
0.5 & $0.502 \pm 0.046$ & $9 \%$ & $100 \%$ \\
1.0 & $0.904 \pm 0.065$ & $7 \%$ & $90 \%$ \\
5.0 & $5.51 \pm 0.18$ & $3 \%$ & $110 \%$ \\
\hline
\end{tabular}




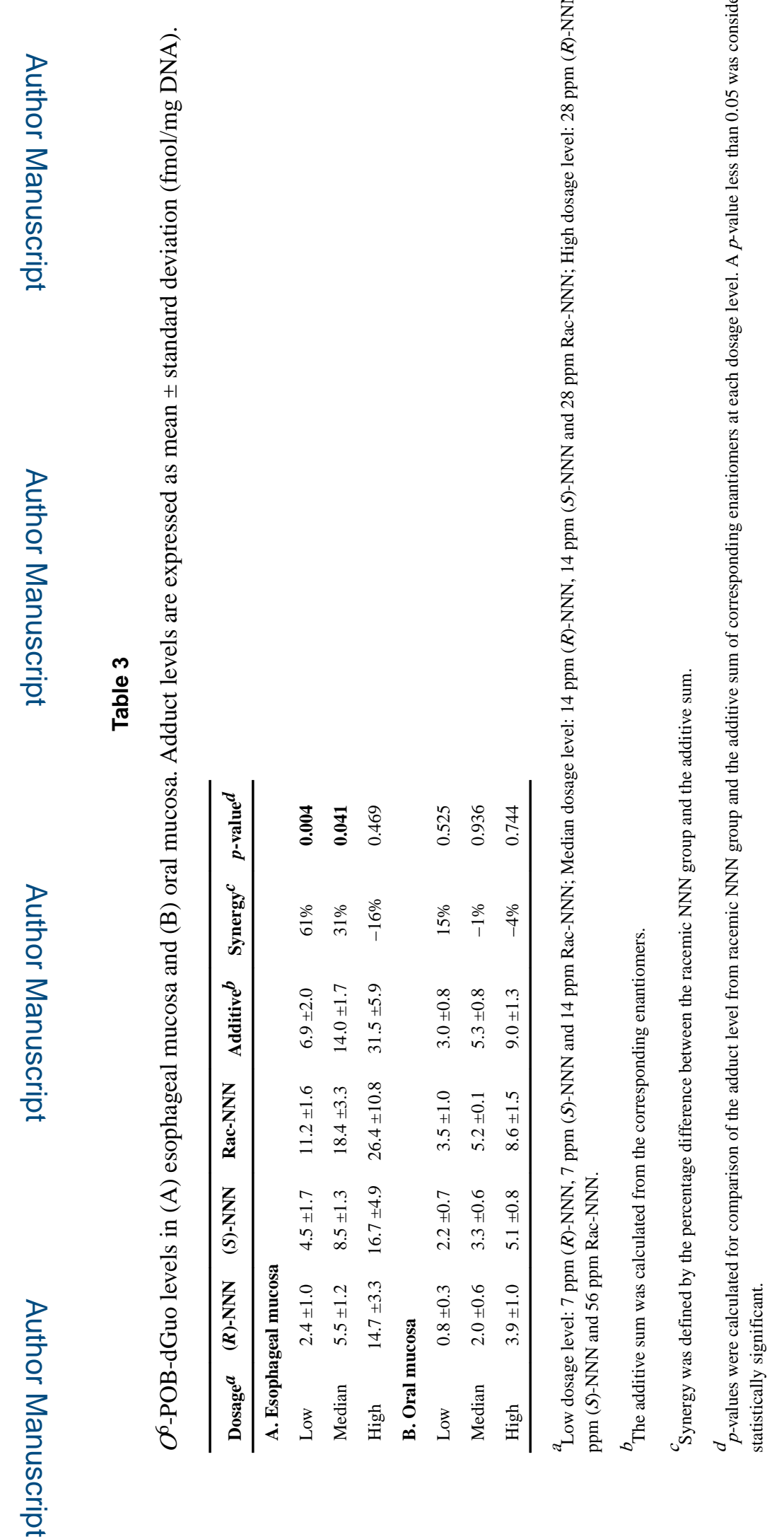

Chem Res Toxicol. Author manuscript; available in PMC 2016 December 20. 


\section{Table 4}

$O^{6}$-POB-dGuo levels in (A) nasal respiratory mucosa, (B) nasal olfactory mucosa. Adduct levels are expressed as mean \pm standard deviation (fmol/mg DNA).

\begin{tabular}{lcccc}
\hline Dosage $^{a}$ & $(\boldsymbol{R})$-NNN & $(\boldsymbol{S})$-NNN & Rac-NNN & Additive $^{b}$ \\
\hline \multicolumn{4}{l}{ A. Nasal respiratory mucosa } \\
Low & $8^{c}$ & $\mathrm{ND}^{d}$ & $16 \pm 3$ & $\mathrm{NA}^{e}$ \\
Median & $22 \pm 3$ & $9 \pm 1$ & $24 \pm 6$ & $31 \pm 3$ \\
High & $31 \pm 5$ & $23 \pm 4$ & $41 \pm 3$ & $54 \pm 7$ \\
B. Nasal olfactory mucosa & & \\
Low & $\mathrm{ND}^{d}$ & $\mathrm{ND}^{d}$ & $3^{c}$ & $\mathrm{NA}$ \\
Median & $4 \pm 1$ & $\mathrm{ND}^{d}$ & $6 \pm 2$ & NA \\
High & $9 \pm 1$ & $3^{c}$ & $12 \pm 4$ & NA \\
\hline
\end{tabular}

${ }^{a}$ Low dosage level: 7 ppm $(R)$-NNN, 7 ppm $(S)$-NNN and 14 ppm racemic NNN; Median dosage level: 14 ppm $(R)-\mathrm{NNN}, 14 \mathrm{ppm}(S)$-NNN and 28 ppm racemic NNN; High dosage level: 28 ppm $(R)-\mathrm{NNN}, 28 \mathrm{ppm}(S)$-NNN and $56 \mathrm{ppm}$ racemic NNN.

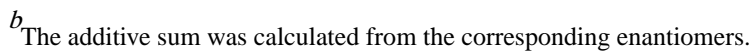

$c$ Two samples were quantified and the third sample was below LOD $(n=2)$.

${ }^{d} \mathrm{ND}$ : not detected, limit of detection (LOD): $7 \mathrm{fmol} / \mathrm{mg}$ DNA for nasal respiratory mucosa; 2 fmol/mg DNA for nasal olfactory mucosa.

NA: not applicable. 